\title{
Vasculitis granulomatosa centrofacial: estudio de seis casos y propuesta para su clasificación.
}

\author{
Guevara S.', Guzmán R. ${ }^{2}$, Peña M. ${ }^{3}$, Rondón F. ${ }^{4}$, \\ González J. ${ }^{5}$, Carreño A. ${ }^{6}$, Sanabria F.', Rojas $C^{3}{ }^{3}$, Iglesias $A^{9}$.
}

\begin{abstract}
Resumen
El número de casos, 2 de 6 localizados y 4 generalizados que hemos presentado demuestran que las formas localizadas mejoran con el tratamiento médico, que probablemente el problema se presente por un defecto localizado en un órgano determinado en la presentación antigénica y que ésta puede mejorar ya que el defecto no es total; en cambio, en la forma generalizada, el antígeno puede alterar la fuente del macrófago y necesitar tratamiento permanente en un individuo genéticamente susceptible. No se debe utilizar el término granuloma letal de la línea media en aquellos casos con diagnóstico específico definido y planteamos la hipótesis de que no debe utilizarse el término granulomatosis localizada de Wegener, sino simplemente granulomatosis o vascuiitis granulomatosa localizada.
\end{abstract}

Con la colaboración de COLCIENCIAS, según contrato 094-93.

\section{Summary}

The number of cases, 2 of 6 localized and 4 generalized, which are presented, demonstrate that localized forms improve with medical treatment. Probably the problem is present due to a localised defect in a determined organ with antigenic presentation. This could improve since the defect is not a total change in the generalized form; the antigen could alter the macrophage source and could necessitate permanent treatment in a genetically susceptible person. The term lethal granuloma should not be used in those cases with a specifically defined diagnosis and the hypothesis is advanced that theterm granulomatosis localised by Wegenershould not be used, simply granulomatosis or localised vasculitis granuloma.

\footnotetext{
Remautólogo, Universidad de América, Ecuador.

2 Instructor asistente, Facultad de Medicina. Hospital San Juan de Dios, Reumatología, Universidad Nacional de Colombia.

3 Profesor asociado, Facultad de Medicina; Jefe de la Unidad de Reumatología, Hospital San Juan de Dios, Universidad Nacional de Colombia.

4 Instructor asistente. Facultad de Medicina. Hospital San Juan de Dios. Reumatologia, Universidad Nacional de Colombia.

5 Profesor asistente, Facultad de Medicina, Hospital San Juan de Dios, Reumatologia, Universidad Nacional de Colombia.

- Profesor asociado, Facultad de Medicina; Jefe de Nefrologia, Hospital San Juan de Dios, Universidad Nacional de Colombia.

7 Residente I de Neumologia, Hospital San Juan de Dios.

- Bacterióloga, Laboratorio de Reumatoiogía. Hospital San Juan de Dios.

g Profesor asistente. Facultad de Medicina, Hospital San Juan de Dios, Universidad Nacional de Colombia; Director, Instituto Nacional de Salud, Santafé de Bogotá, Colombia.
} 
Las lesiones granulomatosas de la línea media, asociadas o no a vasculitis, son parte de un grupo de enfermedades que comprenden lesiones localizadas y destructivas de la nariz, tejidos faciales profundos (formas localizadas), o que pueden generalizarse y afectar los pulmones, el sistema nervioso, la piel y los riñones (1).

Friedmann (2) diferenció los granulomas letales de la línea media (GLM) en dos grupos, con base en los hallazgos histológicos. El primer grupo, el denominado granuloma no cicatrizante de la nariz de tipo Stewart y, el segundo, es el de tipo Wegener que toma la forma de granuloma de células gigantes de carácter necrotizante.

La granulomatosis letal de línea media era considerada muy poco frecuente, de curso agresivo y asociada a desórdenes linfoproliferativos, representada por cuatro entidades: enfermedad destructiva idiopática de la línea media, granulomatois de Wegener, reticulosis polimorfa y linfoma nasal (3).

El hallazgo de granulomas nasales aislados no es específico, porque ocurren en el $1 \%$ de los pólipos nasales (4). Los granulomas de la línea media tienen un amplio diagnóstico diferencial y su detección requiere una buena historia clínica y el análisis cuidadoso de estudios complementarios como estudios radiológicos, bacteriológicos e histopatológicos que constituyen la base de un diagnóstico exacto de GLM (5).

A pesar de los informes de la literatura médica sobre la granulomatosis o vasculitis de la línea media de la cara, aún persiste la confusión en los centros académicos y científicos sobre esta patología. Debido a esta situación, hay problemas para hacer el diagnóstico a nuestros pacientes, retardándose la terapéutica, lo que aunado a una falta de experiencia, puede ocasionar su muerte.

La falta de claridad en torno a estos trastornos ha sido creada por los mismos médicos; consideramos que estas patologías deben estudiarse con criterios clínicos e histológicos para así poder individualizar la entidad o el síndrome clínico. En algunos casos, el diagnóstico es inicialmente difícil, pero, la histopatología y la historia natural de la enfermedad son de valiosa ayuda en su elucidación.

La etiopatogenia de las granulomatosis de la línea media es desconocida; puede ser una alteración de tipo inmunológico, caracterizada por la presencia de uno o múltiples agentes que interactúan inicialmente con los macrófagos, ocasionando un defecto en la presentación ántigénica. Esto produciría liberación de citocinas $y$ arribo de linfocitos $T$ hacia el sitio de la agresión. Entre estas citocinas, se producirían factores inhibidores de la movilidad de los macrófagos y monocitos cuya expresión patológica final es la formación de un granuloma. Otros consideran que son secundarias a un aumento de sensibilidad localizada (hipersensibilidad) (1) o que corresponden a lesiones inmunoproliferativas de linfocitos T (6).

La demostración de los anticuerpos anticitoplasmáticos (ANCA) es una ayuda que puede complementar el diagnóstico de cierto tipo de vasculitis, como la granulomatosis de Wegener (7). Sin embargo, su presencia per se no es diagnóstica de granulomatosis de Wegener, entidad en la que deben primar los aspectos clínicos y patológicos.

Las lesiones granulomatosas pueden ser localizadas (tabiquete nasal, sistema nervioso, tracto gastrointestinal, pulmón, piel) o ser generalizadas comprometiendo múltiples órganos. Estudiamos un grupo de seis pacientes, de los cuales dos tenían compromiso localizado en el tabique nasal. Se obtuvo curación de su cuadro clínico después de 12 años y 18 meses de estar sin tratamiento.

De acuerdo con nuestra experiencia y la observación de estas patologías en el Hospital San Juan de Dios, estableceremos inicialmente una clasificación de los síndromes granulomatosos de la línea media; luego, informaremos la evolución clínica de los pacientes con granulomatosis localizada y describiremos algunos pacientes con granulomatosis sistémica de Wegener. 


\section{Clasificación de síndromes granulomatosos de la línea media}

1. Síndrome de Wegener

$$
1.1 \text { ¿Localizado? }
$$

1.2 Generalizado

1.3.1 Asociado a lesiones granulomatosas y vasculitis

1.3.2 ¿Solamente lesiones granulomatosas?

1.3.3 ¿Solamente vasculitis?

2. Granulomatosis linfomatoide (linfoma)

2.1 Reticulosis polimorfa. Fase de pre-linfoma

2.2 Linfoma

3. Síndrome de Churg-Strauss

4. Granulomatosis idiopática de la línea media.

4.1 Con vasculitis

4.2 Sin vasculitis

5. Síndrome de superposición

6. Rinitis granulomatosa

6.1 MICOSIS

6.1.1 Aspergilosis

6.1.2 Aspergiloma de la nariz, los senos paranasales y las órbitas

61.3 Paracoccidiodomicosis y norteamericana

6.1.4 Mucormicosis

61.5 Rinosporidiosis

6.1.6 Ficomicosis

\subsection{BACTERIANAS}

6.2.1 TBC (lupus vulgar)

6.2.2 Estafilococia maligna de la cara

6.2.3 Por asociación de gérmenes grampositivos y gramnegativos.

6.2.4 Lepra lepromatosa

6.2.5 Actinomicosis

6.2.6 Sífilis

6.3 PARASITARIA

6.3.1 Leishmaniasis

6.3.2 Miasis

7. Rinitis atrófica

7.1 Primaria

7.2 Secundaria

8. Neoplasias

8.1 Otros tipos de linfoma diferentes de la reticulosis polimorfa
8.2 Carcinomas
8.3 Sarcomas (rabdomiosarcomas)

9. Crioinmunoglobulinemias

9.1 Tipo II

10. Misceláneas

10.1 Histiocitosis

10.2 Sarcoidosis

10.3 Granuloma inducido por colesterol

10.4 Pólipos inflamatorios de la nariz y de los SPN

10.5 Granuloma por cuerpo extraño (esteroide, parafina).

10.6 Cocaína. Produce inflamación centrofacial sin lesión granulomatosa.

\section{Informe de casos}

\section{Caso 1}

Hombre de 34 años, procedente de Barranquilla (figura 1A). La enfermedad se inició en enero de 1979 con rinorrea y obstrucción nasal. Consultó a un otorrinolaringólogo quien realizó diagnóstico de pansinusitis y le inició tratamiento con antibióticos y punción maxiliar. En noviembre de 1979, debido a la persistencia de la sintomatología, se realizó procedimiento de Caldwell-Luc y etmoidectomía derecha. A pesar de ello, el paciente presentó edema de la base de la nariz y maxilar, hipertermia y eritema. Se tomó biopsia de tejido pericondral que mostró tejido fibrohialino y pericondritis crónica (figura 1B, $1 \mathrm{C}$ y $1 \mathrm{D}$ ). Recibió tratamiento con esteroides $30 \mathrm{mg} /$ día después de descartarle una lesión granulomatosa infecciosa por gram negativos, una micosis o TBC. El paciente entró en remisión y voluntariamente suspendió los glucocorticoides. Cuatro semanas después hubo reactivación de su enfermedad con incremento del eritema y del edema en la región maxiliar y en la base de la nariz; además, se observó deformación nasal en silla de montar. Se practicó nueva biopsia de piel, hasta el periostio que mostró angeitis necrotizante con eosinofilia y reacción granulomatosa y se confirmó el diagnóstico de granulomatosis de Wegener localizada. 


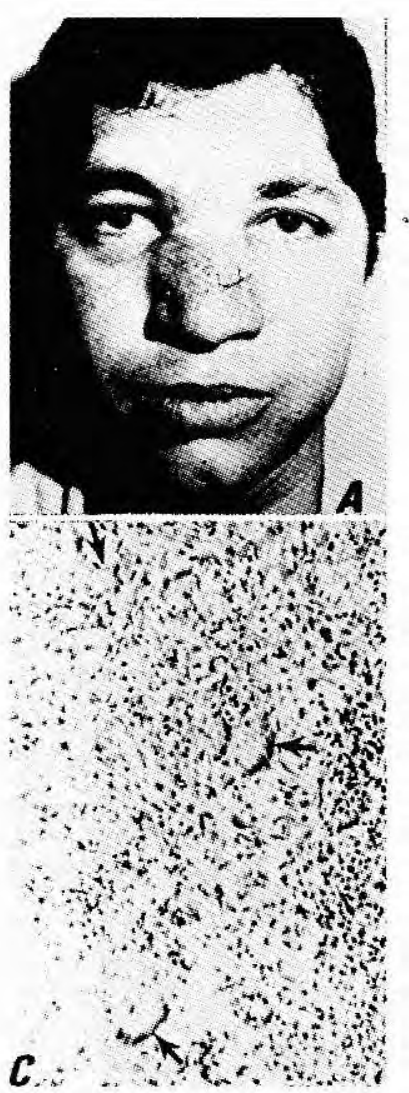

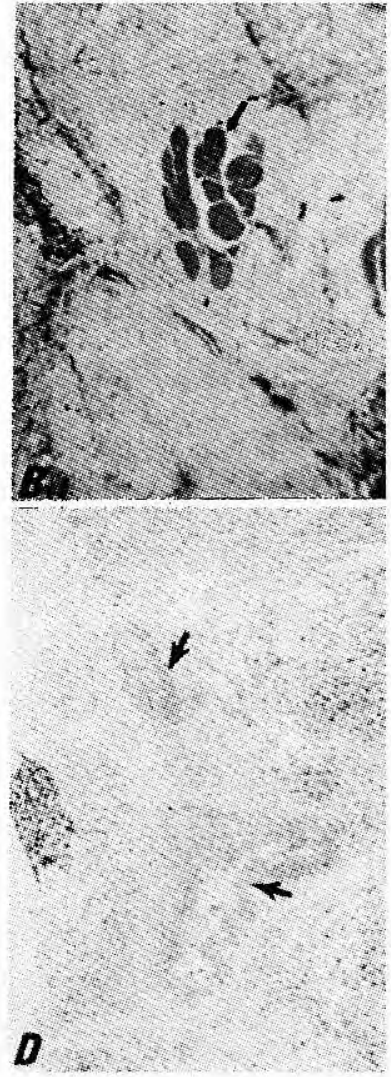

Figura 1A. deformidad nasal en silla de montar.

Figura 1B. biopsia de tejido pericondrial: Tejido fibrohialino y pericondritis crónica.

Figura 1C. biopsia de piel: angeitis necrotizante con eosinofilia y reacción granulomatosa.

Figura 1D. biopsia de piel hasta el periostio: vasculitis necrotizante, eosinofilia y granulomas.
Los estudios paraclínicos, no demostraron compromiso pulmonarni renal. Se le inició tratamiento con $30 \mathrm{mgs} /$ día de prednisolona y $100 \mathrm{mgs} /$ día de ciclofosfamida (Endoxán ()). Tres semanas después presentó franca mejoría de su cuadro clínico y al año estaba asintomático. Se le practicaron pruebas de función renal y análisis de orina cada cuatro semanas por dos años, sin encontrarse ninguna complicación. Inicialmente se observó un aumento de la sedimentación globular de 40-50 $\mathrm{mm}$ por el método de Westergren que se normalizó con el tratamiento. Como secuela de la enfermedad refiere hiposmia. No se demostró alteración de tipo inmunológico. Doce años después del tratamiento se encuentra asintomático.

\section{Caso 2.}

Mujer de 18 años; su enfermedad se inició en junio de 1990 por epistaxis recidivante, en ocasiones, severa. En enero de 1991 notó deforma- ción del septum nasal por lo que consultó al servicio de ORL del ISS de Barranquilla (figura 2A). En vista de la deformación septal, se programó para una septoplastia en febrero de 1991. Al observar un reblandecimiento gelatinoso y una mucosa de aspecto rosado, se le practicó una biopsia que mostró vasculitis de pequeños vasos, arteritis y lesiones granulomatosas. Se plan-tea el diagnóstico de síndrome necrotizante de la línea media. Se descartó una etiología por gérmenes bacterianos o micóticos. Se enviaron bloques y láminas a la Universidad de Illinois en Chicago, que informó lo siguiente: "El epitelio de la superficie aparece intacto. El área subepitelial contiene un infiltrado inflamatorio mononuclear denso. Aumento original 40x (figura $2 \mathrm{~B}$ y $2 \mathrm{C}$ ) la tinción con inmunoperoxidasa del infiltrado inflamatorio es positiva; sólo para el marcador CD45RO (memory cells). Aumento original $400 x . "$ 
Los exámenes paraclínicos revelaron: hemoglobina: 12,2; hematocrito: 37; leucocitos: 5.800 (N:52\%, L:47\%);VSG: $37 \mathrm{~mm}$; plaquetas: 274.000 ; glicemia: $74 \mathrm{mg} / \mathrm{dl}$; calcio: $9,3 \mathrm{mg} / \mathrm{dl}$; creatinina: 0,7 mg; IgG: $323 \mathrm{UI} / \mathrm{ml}$ (N 92-207), IgA: $306 \mathrm{UI} /$ ml (N 54-268); ASTO: $800 \mathrm{UI} / \mathrm{ml}$; RA test: negativo; VDRL: negativo; anticuerpos antinucleres: negativos, C-ANCA y P-ANCA y anticardiolipina, negativos.

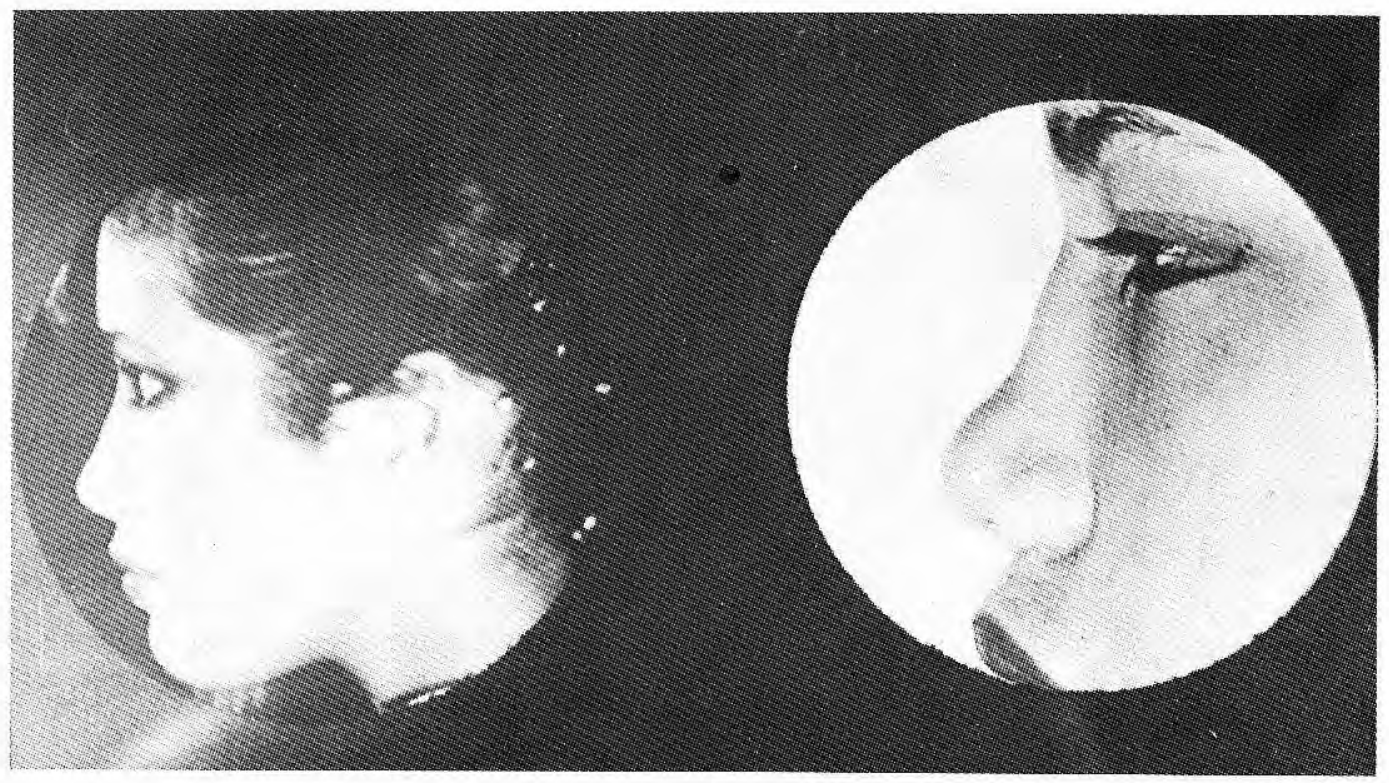

Figura 2A. Deformidad del septum nasal.

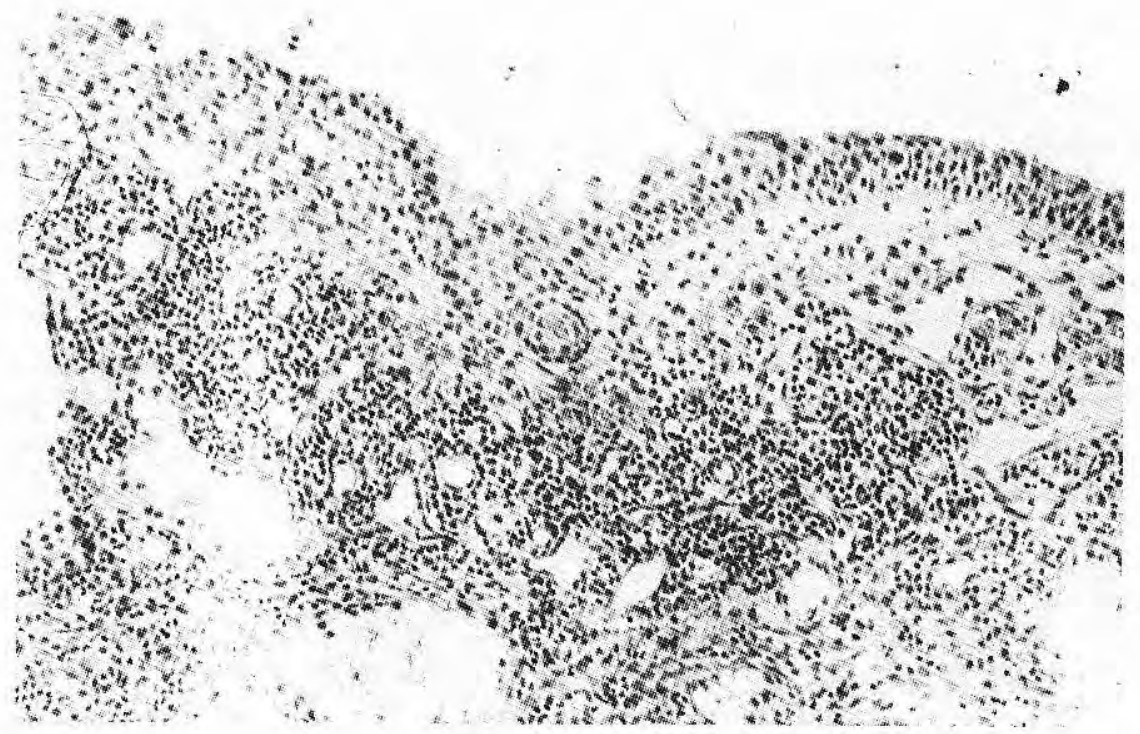

Figura 2B. Infiltrado inflamatorio crónico; subpoblación celular CD45RO (memory cells). Tinción con inmunoperoxidasa. 


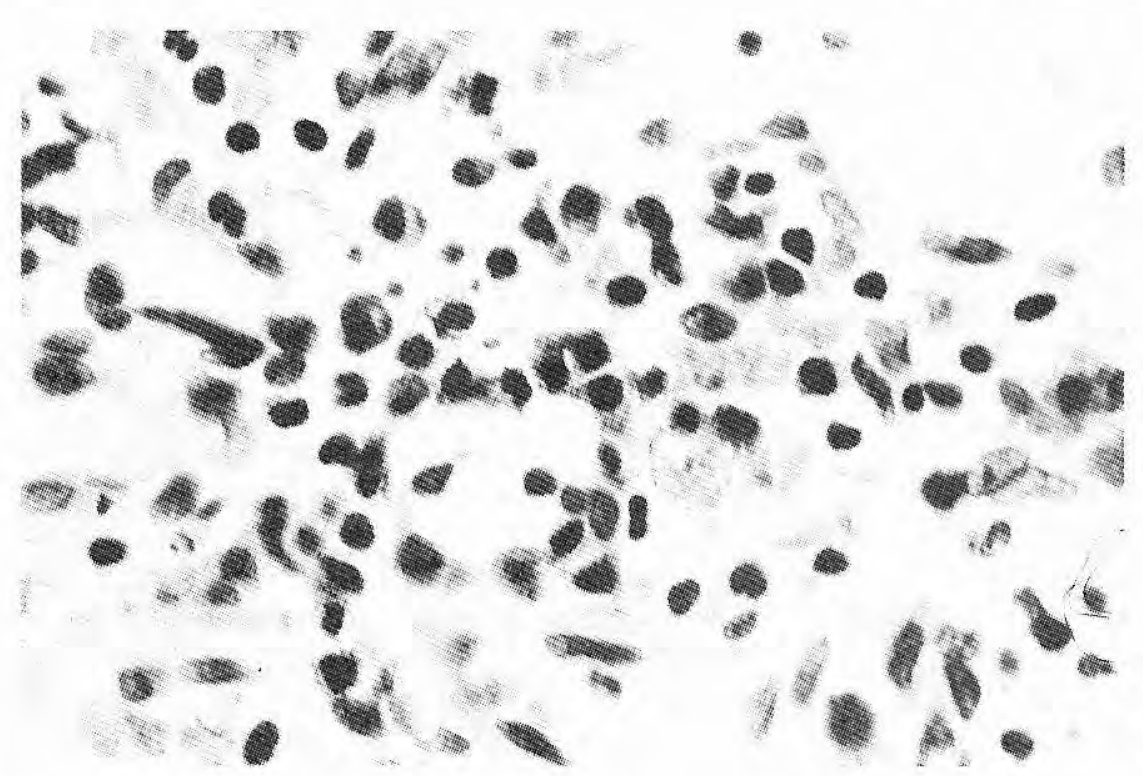

Figura 2C. Subpoblación celular CD245 RO (memory cells).

\section{Caso 3.}

Mujer de 28 años, natural de Florián y procedente de Bogotá. Consultó en mayo de 1991 por cuadro de tres meses de evolución, consistente en dolor frontal y facial intenso, asociado con rinorrea serohemática, otorrea purulenta bilateral, con disminución de la agudeza auditiva y cefalea; luego, apareció úlcera dolorosa sublingual; a malestar general, artralgias y pérdida de peso (más o menos 5 kilos en el mes). Con diagnóstico de sinusitis crónica agudizada, recibió tratamiento con cefalosporina de primera generación con mejoría parcial de sus síntomas. Desde entonces empezó a presentar fiebre vesperal, escalofríos, diaforesis, pérdida de peso y, dos meses después, tos con expectoración hemoptoica y deformidad progresiva del dorso nasal con nariz en silla de montar (figura 3). No existían antecedentes previos de importancia. El examen físico reveló signos vitales normales, nariz en silla de montar asociada con reabsorción del cartílago cuadrangular del septum nasal, además de estenosis vestibular y lesiones costrosas en la mucosa nasal. La palpación de los senos paranasales era dolorosa y la otoscopia mostraba tímpanos enrojecidos, opacos, retraídos, sin otorrea y con perforación puntiforme en el cuadrante anteroinferior del oído derecho; existía una lesión ulcerativa sublingual de fondo blan- quecino de $1 \mathrm{~cm}$ de diámetro que se extendía desde el conducto de Warton hasta la mucosa lingual dental; cursaba con congestión conjuntival y epiescleritis y lesión cicatrizal localizada en el área nasal inferior.

La intensidad de los ruidos respiratorios se encontraba disminuida en los $2 / 3$ inferiores del hemitórax derecho. El resto del examen era normal; se hizo diagnóstico de neumonía bacteriana.

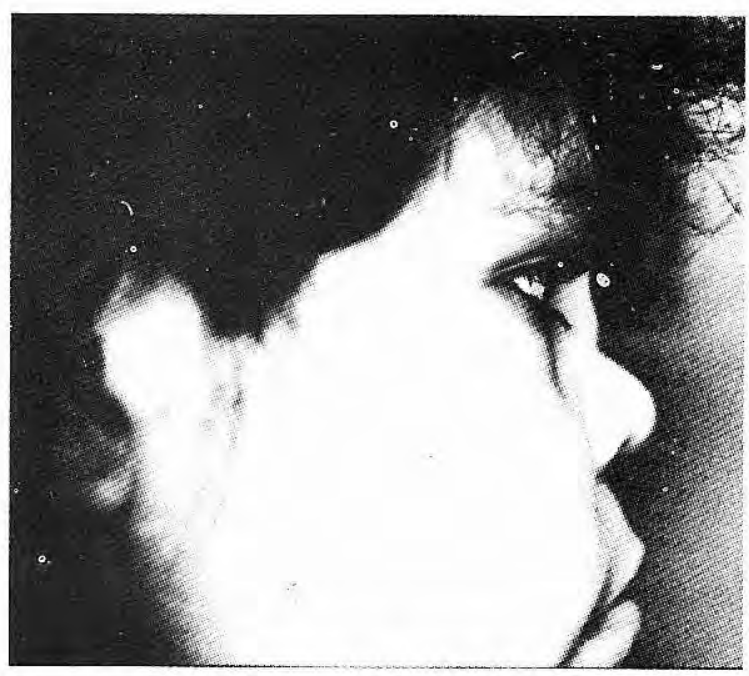

Figura 3. Deformidad nasal en silla de montar. 


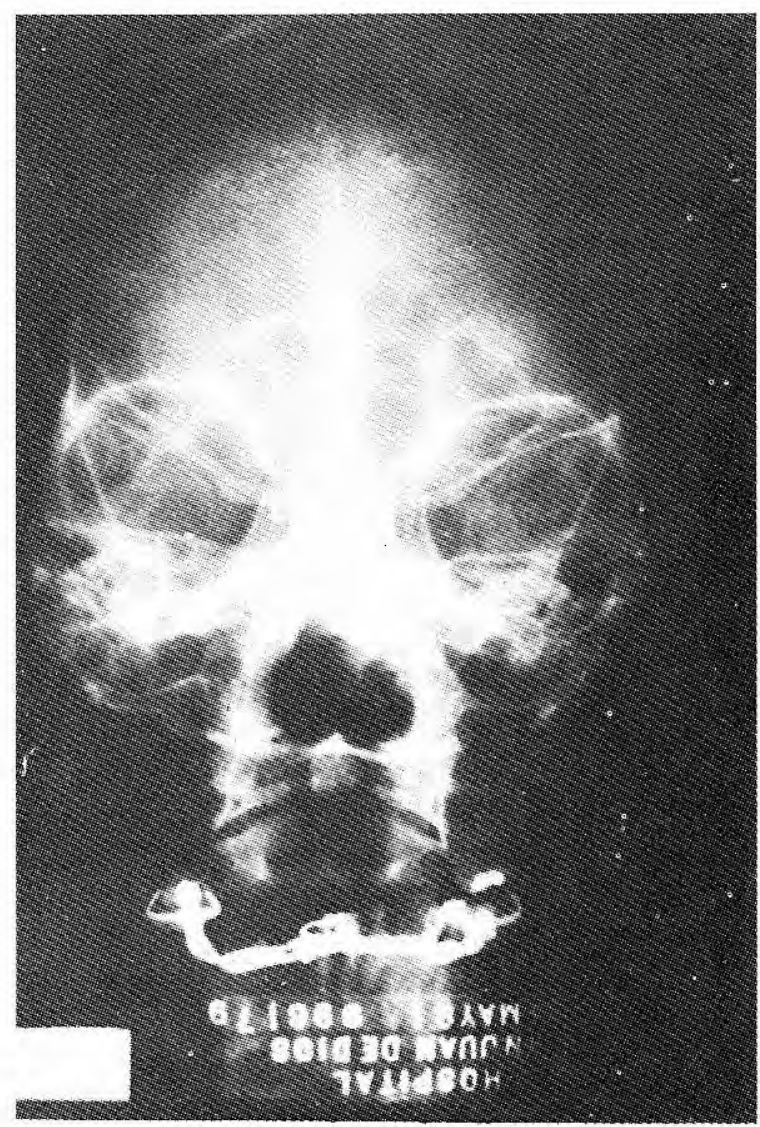

Figura 3A. Reabsorción parcial de cornetes y de SPN.
Los exámenes paraclínicos tomados incialmente mostraron: hemoglobina $11,3 \mathrm{~g} \%$; hematocrito, 34\%; VSG: 52 mm/1h; leucocitos 15.700; N 94\%, L $6 \%, E 1 \%$; parcial de orina: albúmina: trazas, leucocitos, 3-5/campo; glóbulos rojos: incontables; BUN 10 mg\%; creatinina: 1,25 mg\%; depuración de creatinina: $40 \mathrm{cc} / \mathrm{min}$; proteinuria: 100 mg/24 h; electrolitos séricos: HIV: negativo; $\mathrm{Ca}$ sérico: normal; VDRL: no reactivo; ANCA +: patrón citoplasmático granular TPT y TP: normales; plaquetas: 680.000; aspirado de médula ósea: hiperplasia mieloide; hierro sérico: $17 \mu \mathrm{g} \%$ (N 37-145); hemocultivos: negativos; BK en esputo, negativos; PPD: negativo: HIV: negativo; perfil hepático: normal; proteínas séricas: $6 \mathrm{~g} \%$; AAN: 1/640 patrón moteado; C3 y C4 normales; EKG: taquicardia sinusal y alteraciones difusas de repolarización; radiografía de senos paranasales: reabsorción parcial de cornetes y septum nasal (figura 3A).

Placa de tórax: masa de gran tamaño de bordes irregulares y no homogénea en el segmento apical del lóbulo inferior derecho; dos lesiones nodulares, una en la base de cada hemitórax.

TAC de tórax: masa de las características descritas y con tendencia a la cavitación al igual que las otras lesiones.

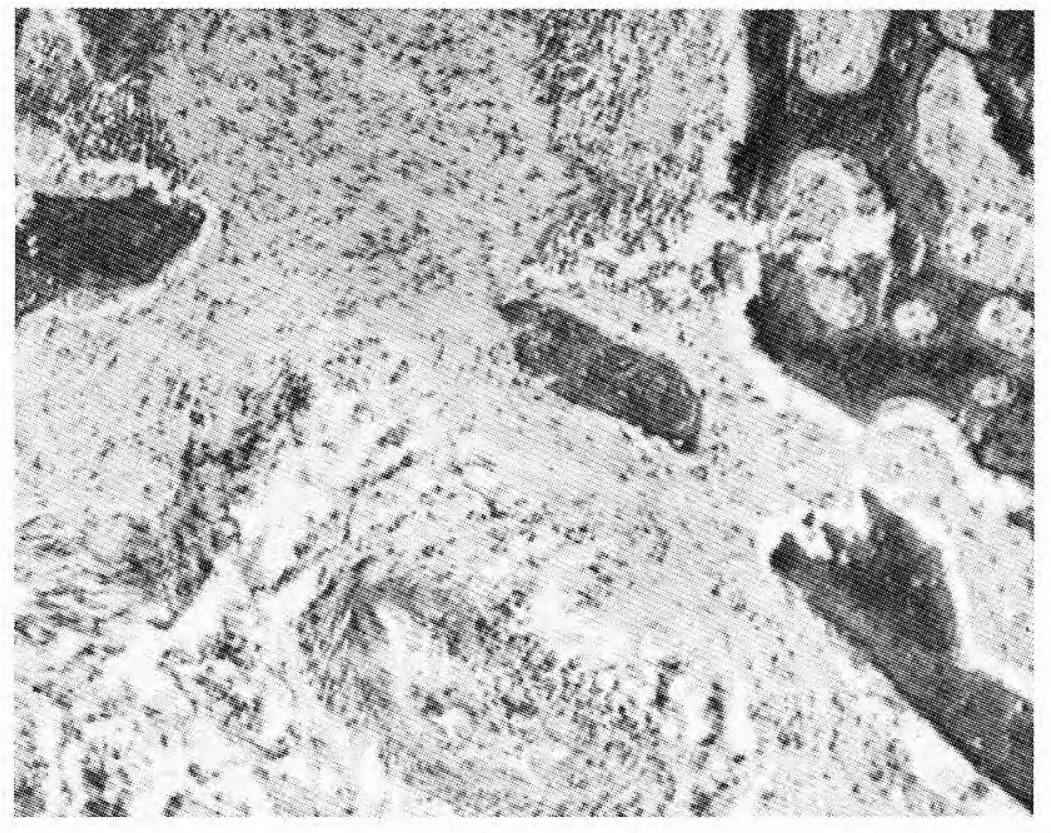

Figura 3B. Biopsia de la úlcera sublingual: inflamación granulomatosa necrotizante, células gigantes multinucleadas y vasculitis de pequeños vasos. 
Endoscopia digestiva: esofagitis grado I y gastritis crónica multifocal.

Fibrobroncoscopia: restos hemáticos en el bronquio segmentario apical del lóbulo inferior derecho y cambios de endobronquitis leves. Biopsias de úlcera sublingual y de la mucosa bronquial: inflamación granulomatosa necrotizane con células gigantes multinucleadas y vasculitis focal de pequeños vasos (figura 3B y $3 \mathrm{C}$ ). Como complicación, pesentó hemorragia de las vías digestivas altas por enfermedad acidopéptica; hipertensión arterial, por lo cual se inició captopril $50 \mathrm{mg} /$ día. Se practicó biopsia renal que reveló glomerulonefritis necrotizante focal proliferativa intra y extracapilar.

Con diagnóstico de granulomatosis de Wegener se inició tratamiento con ciclofosfamida $100 \mathrm{mg} /$ día y prednisolona $1 \mathrm{mg} / \mathrm{kg} /$ día. Presentó mejoría clínica y paraclínica; se adicionó trimetroprim sulfa. En los controles, hubo dramática mejoría del estado general, aumento de las cifras de hemoglobina y hematocrito y mejoría de la depuración de creatinina de $(33 \mathrm{~mL} / \mathrm{min})$ a $77 \mathrm{~mL} /$ min y negativización de los C-ANCA.

\section{Caso 4}

Hombre de 35 años, natural de Sonsón, procedente de Bogotá. Consultó por presentar desde hace 6 meses dolor en la región frontal y facial, rinorrea purulenta y anosmia. Se inició tratamiento con antibióticos sin mejoría, por lo cual cinco meses después se le practicó procedimiento quirúrgico (Caldwell-Luc). El estudio anatomopatológico informó una rinitis granulomatosa ulcerada.Concomitantemente había empezado a presentar edema palpebral, hiperemia conjuntival, epífora y fotofobia intensas; deformidad progresiva del dorso nasal (figura 4); tos con expectoración hemoptoica o purulenta y pérdida de peso.

El examen físico mostró nariz en silla de montar, por reabsorción del cartílago cuadranguiar del septum y múltiples costras hemopurulentas en la mucosa nasal; queratitis marginal subepitelial y congestión conjuntival mixta intensa, áreas de epiescleritis nodular y difusa bilateral y edema palpebral. La auscultación pulmonar reveló respiración ruda y roncus respiratorios diseminados. Los signos vitales y el resto del examen físico fueron normales.

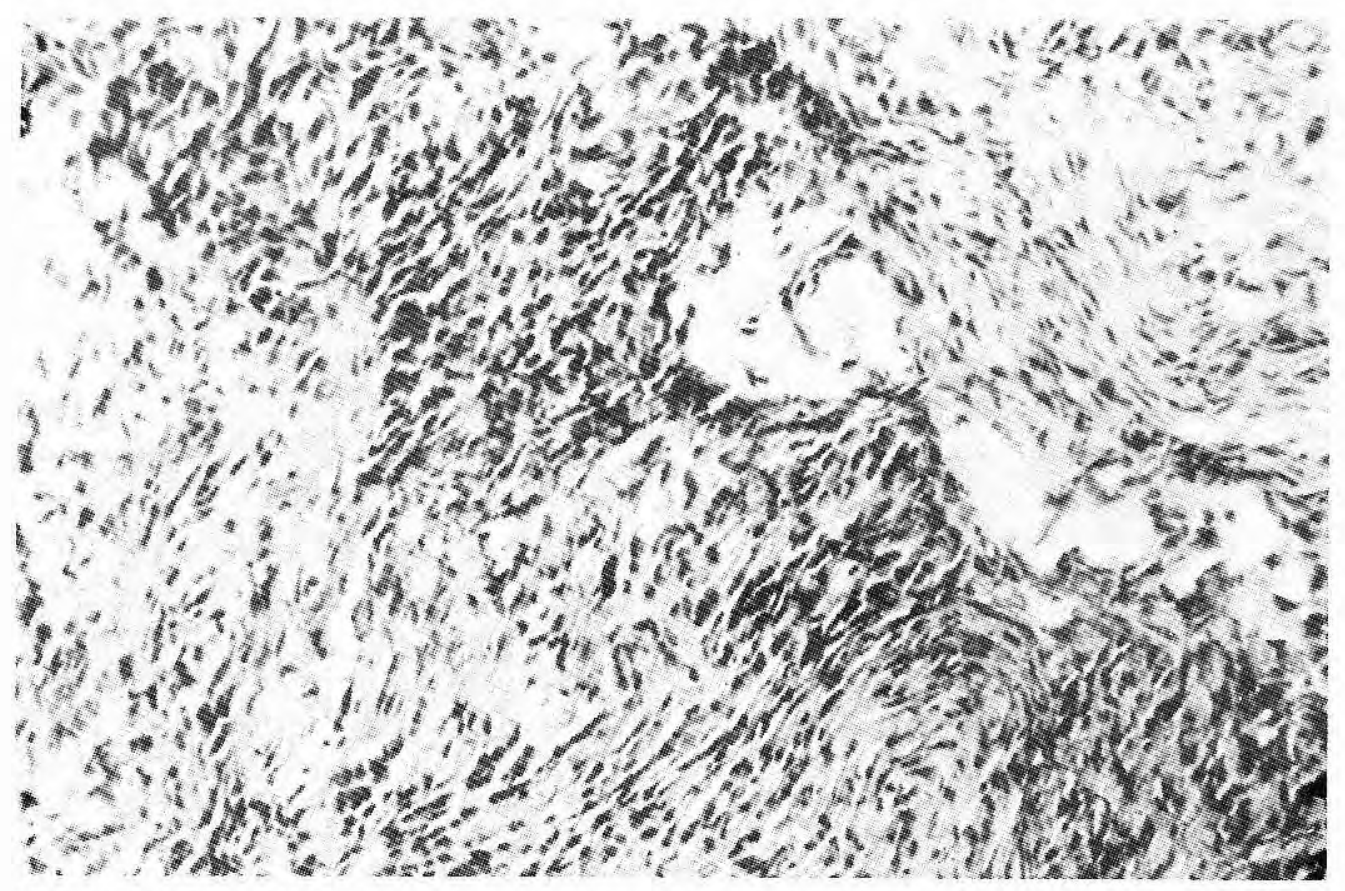

Figura 3C. Biopsia de la mucosa bronquial. Vasculitis granulomatosa necrotizantes y células gigantes multinucleadas. 


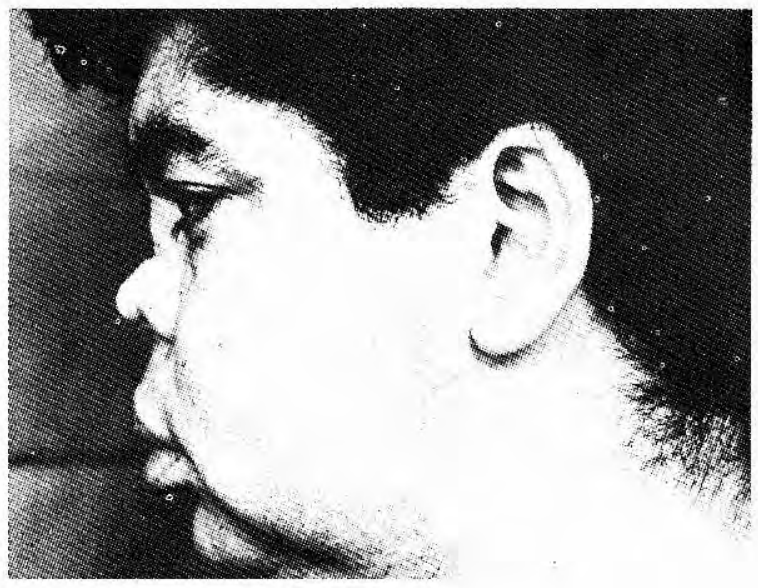

Figura 4. Deformidad del dorso nasal.

Los exámenes paraclínicos mostraron:

hemoglobina: 13,2; hematocrito: 41; VSG: 21 $\mathrm{mm} / \mathrm{h}$; leucocitos: 13.200 , N $88 \%$, L 12\%. Parcial de orina: leucocitos 2-3/campo; hematíes: 40-60/campo. Depuración de creatinina: $35 \mathrm{~mL} /$ min; BUN: 14,7 mg\%; creatinina: 1,1 mg\%; depuración de creatinina $72 \mathrm{cc} / \mathrm{min}$; proteinuria: 90 mg/24h; electrolitos séricos: normales; plaquetas: normales; BK de esputo: negativos; VDRL: no reactivo; FTA-ABS: negativo; HIV: negativo; ANAS: $1 / 640$, patrón moteado: ANCA+, patrón citoplasmático, FR: negativo. Radiografía de se-nos paranasales: velamiento de senos maxilares, frontal derecho y etmoidales. Placa de tórax: lesión nodular de $1 \mathrm{~cm}$ de diámetro proyectada en el lóbulo superior derecho. TAC cerebral: severa sinusitis etmoideomaxilar. Fibrobroncoscopia: tráquea y árbol bronquial con eritema, edemay engrosamiento de mucosas y disminución concéntrica de la luz de los bronquios y lobares. Lesiones vegetantes blanquecinas y hemorrágicas en la tráquea.

En la biopsia de la mucosa traqueal y en el material obtenido durante la cirugía se encontró severo infiltrado de linfocitos, PMN y eosinofilos alrededor de las paredes vasculares; tejido fibromuscular con necrosis y granulomas formados por linfocitos, plasmocitos y células epitelioides. Espirometría: patrón obstructivo leve.
Con diagnóstico de granulomatosis de Wegener se inició tratamiento con ciclofosfamida $50 \mathrm{mg} /$ día y manejo ocular tópico con glucocorticoides. Inicialmente hubo mejoría de los síntomas, pero, cuatro meses después se recrudecieron las manifestaciones oculares por lo cual se incrementó la dosis de ciclofosfamida a $100 \mathrm{mg} /$ día, presentando mejoría progresiva; paralelo con la mejoría clínica hubo negativización de los ANCA. En diciembre de 1992, presentó escleritis severa y necrosis por lo que oftalmología inició ciclosporin tópico al $2 \%$ cada 4 horas y nuestro servicio aumentó ciclofosfamida a $150 \mathrm{mg} /$ día y prednisona $60 \mathrm{mg} /$ día con mejoría.

\section{Caso 5.}

Mujer de 47 años, natural de Facatativá y procedente de Bogotá; consultó por tos con expectoración hemoptoica. La enfermedad se inició hace dos meses con un síndrome gripal, con disfonía, ronquera, secreción nasal purulenta y, luego, con obstruccción nasal por lo cual se diagnósticó sinusitis aguda y recibó tratamiento con Bactrim sin obtener mejoría. Quince días antes del ingreso presentó tos con expectoración hemoptoica y aparecó lesión ulcerativa en el paladar duro, dolorosa y sangrante de la cual se aisló Staphilococcus aureus. Recibió tratamiento con dicloxacilina, sin mejoría. Manifestó, además, parestesias en el área de la mano izquierda; debilidad distal progresiva, disminución de la agudeza visual con marcado predominio derecho. Durante el tiempo de evolución, manifestó fiebre no cuantificada, astenia, adinamia y deterioro del estado general.

Antecedentes: hipertensión arterial diagnosticada hace 10 años para lo cual recibe captopril y prazocín, caída del cabelllo y pérdida de peso.

Examen físico: ingresó con tensión arterial de 130/70; frecuencia cardíaca $84 / \mathrm{min}$; voz nasal, cabello escaso, obstrucción nasal bilateral por costras con pintas negras de sangre; en la boca hay úlcera del paladar duro de $4 \times 3 \mathrm{~cm}$. Tórax: movilización abundante de secreciones. Sinovitis moderada de interfalángicas y metacrapofalángicas bilaterales del codo izquierdo y de la rodilla izquierda; además, várices con dermatitis ocre pigmentaria en miembros inferiores; $\mathrm{SN}$ : plejia del VI par derecho; disminución de la fuerza dis- 
tal e hipoalgesia del borde cubital de la mano izquierda.

Diagnóstico de ingreso: lesión ulcerativa de la línea media: a) carcinoma epiermoide?; b) linfoma?; c) granulomatosis de Wegener?.

Paraclínicos: VSG: 50 mm; hemoglobina: 10,9; hematocrito: $23 \%$; glicemia: 117 ; creatinina: 4,4 ; BUN 56 mg; Na: 136, K:3,6; parcial de orina: hematuria (4 a 6/campo).

Radiografía de tórax: normal; ANCA: positivo 1/ 20, patrón ganular fino; AAN: negativo. ORL: toma de biopsias: vasculitis necrotizante con granulomas.

Oftalmología: conjuntivitis, oclusión de la arteria ciliar posterior y hemorragias retinianas del ojo derecho.

La paciente pesentó un brote en el tórax y los miembros superiores que clínicamente sugirieron vasculitis. Se inició tratamiento con Endoxán $100 \mathrm{mg} /$ día y prednisona $60 \mathrm{mg} /$ día con notable mejoría y cicatrización de la lesión ulcerativa. Como complicación presentó hematuria. No fue posible hacer biopsia renal. Evolucionó adecuadamente. Diagnóstico final: granulomatosis de Wegener.

Caso 6.

Mujer de 37 años. Desde hace varios meses presenta fiebre, tinitus, odinofagia, otalgia derecha y artritis de la rodilla derecha, que remite. Dos meses depués presentó congestión ocular, con epífora y fotofobia, inicialmente en el ojo izquierdo y un mes más tarde en el derecho. Mejoró con corticoides (gotas oftálmicas).

A los seis meses se reactivó su enfermedad con fiebre, cefalea y lesión papulo-eritematosa dolorosa, ubicada en los genitales externos, para lo cual le formularon corticoides orales (prednisolona $30 \mathrm{mg} /$ día). Se aumentó la dosis a $90 \mathrm{mg}$ y presentó facies cushingoide. Luego de un mes, se decidió disminuir la dosis en forma progresiva, exacerbándose la sintomatología anterior y adicionándose: tos, parálisis facial izquierda súbita, orinas oscuras, pérdida de la visión en el ojo derecho, anorexia, adinamia, sudoración nocturna y pérdida de peso.
Examen físico: tensión arterial: 110/70 mm Hg; frecuencia cardíaca 120-160; temperatura $38^{\circ} \mathrm{C}$; peso 43,5 kilos. Uveitis derecha con púpila isocórica, úlcera conjuntival y hemorragia en cámara anterior, asimetria facial periférica izquierda. La agudeza visual de 20/30+ en el ojo izquierdo y sólo percepción luminosa en el derecho. En los oídos presentaba condritis auricular izquierda con hipoacusia bilateral mixta demostrada por audiometría. Tenía hepatomegalia dolorosa. Una úlcera genital de más o menos $6 \mathrm{~cm}$ de diámetro, profunda, con foco necrótico y secreción purulenta, localizada en el labio mayor derecho.

Paraclínicos:cuadro hemático: moderada leucocitosis, con neutrofilia; VSG aumentada; uroanálisis: hematuria, cilindruria y albuminuria. Factor reumatoideo 1:160. Placa de tórax: lesiones nodulares, especialmente en el pulmón izquierdo. Con lo anterior se planteó la posibiidad de granulomatosis de Wegener.

Paraclínicos realizados posteriormente señalaron empeoramiento, así: hemoglobina $9,8 \mathrm{~g} / \mathrm{dL}$; hematocrito $30 \%$; VSG $59 \mathrm{~mm} /$ hora; leucocitos $11.600 \mathrm{~mm} 3$; neutrófilos $76 \%$ linfocitos $21 \%$. Uroanálisis: mostró hematuria, cilindruria, albuminuria y hubo un rápido deterioro de la función renal caracterizado por creatinina sérica de 4,05 mg/dL, nitrógeno ureico de $54 \mathrm{mg} / \mathrm{dL}$, depuración de creatinina $9 \mathrm{cc} / \mathrm{min}$ y proteinuria de $680 \mathrm{mg} / 24$ horas. Inmunoglobulinas $\lg$ A 2410 $\mathrm{mg} / \mathrm{dL}$, anticuerpos antinucleares y factor reumatoideo negativos, complemento normal.

La radiografía de mastoideos reveló pérdida de la neumatización de las celdillas mastoideas del lado derecho sugiriendo una otitis media crónica; el elecrtocardiograma mostró taquicardia sinusal, la ecocardiografía fue normal.

La biopsia renal fue informada como glomerulonefritis necrotizante focal y segmentaria. Se hizo diagnóstico de GW y se reinició tratamiento con prednisolona $50 \mathrm{mg} /$ día V.O. Luego, ciclofosfamida $50 \mathrm{mg} /$ día V.O. La biopsia nasal fue informada como rinitis crónica.

La paciente mejoró luego de la instauración de la ciclosfosfamida, recuperóla agudeza visual, mejoró la depuración de creatinina, desaparece la 
cilindruria y la hematuria. La evolución radiológica fue dramática, desaparecieron las lesiones pulmonares luego de 20 días de tratamiento con ciclofosfamida.

\section{Discusión}

La primera descripción de GLM se realizó en 1897 cuando McBride (8) informó un caso de "destrucción rápida de la nariz y la cara". En 1954 Godman y Churg (9) describieron las características patológicas de la granulomatosis de Wegener y el compromiso de vasculitis necrotizante que comprometía arterias y venas de pequeño calibre. Esto permitió separar la granulomatosis de Wegener como uno de los componentes del granuloma letal de la línea media. En 1959, Blatt y col. (10), después de una amplia revisión del tema, concluyeron como Friedman (11) que ésta es una enfermedad con dos variantes: localizada como granuloma letal de línea media y generalizada como granulomatosis de Wegener. Postularon como etiología una hipersensibilidad. En ese mismo año, Walton (12) dividió los granulomas no cicatrizantes de la cara en tres categorias: granulomatosis de Wegener, granuloma maligno clásico (granuloma letal de línea media) y sarcoma reticulocelular. El término granulomatosis de Wegener fue reservado para los casos con ulceración nasal, amplia granulomatosis y lesiones vasculares a través del cuerpo. Caracterizó esta enfermedad en cuatro aspectos:

1. "Historia natural con dos fases: una de infección nasal o pulmonar crónica, con posterior evolución a una inflamación granulomatosa que compromete múltiples órganos".

2. "La lesión del tracto respiratorio es usualmente superficial sin extensión a la piel de la cara". No obstante, se han descrito casos con compromiso de la piel de la cara.

3. "El curso clínico es crónico y recidivante, ocasionando la muerte en 5 meses", antes de la terapia con ciclofosfamida.

4. "Los rasgos patológicos son: ulceraciones granulomatosas en el tracto respiratorio y células gigantes granulomatosas dispersas con lesiones necrotizantes de pequeños vasos".
En este estudio tratamos de resolver el siguiente interrogante. La granulomatosis localizada en un órgano se conoce tradicionalmente como granulomatosis de Wegener localizada (nariz, SPN, tráquea, bronquios, uretra, etc.) (13). Planteamos la hipótesis que éstas son reacciones patológicas órgano-específicas que se presentan cuando existe un defecto en la presentación antigénica en una estructura anatómica cualquiera, que puede tener una autoresolución o curarse con un tratamiento adecuado como lo observamos en los casos presentados. Además, en ninguno de los casos descritos como granulomatosis de Wegener localizada, existe un informe en el cual ésta se generalice y, además, no reune los criterios de la American College of Rheumatology para granulomatosis de Wegener (14). Este concepto de un defecto del macrófago localizado en tejido u órgano en forma aislada lo hemos demostrado en el compartimiento articular en pacientes con AR(15). Burston en 1959 (16) señaló que antes de considerar un diagnóstico de granuloma letal de la línea media deben excluirse enfermedades como: sífilis, tuberculosis, neoplasias, infección por hongos, anemia o discrasias sanguíneas, rinoscleroma, sarcoidoisis, leishmaniasis e histiocitosis. También manifiesta que, aún despúes de excluir las causas anteriores, el médico tiene el problema de cómo llamar estos procesos. El término más común es el de granuloma letal de línea media. En Europa se conocía como granuloma maligno o granuloma gangrenoso.

En 1966, Eichel y col. (18) de la Clínica Mayo informaron 33 linfomas de la nariz, 24 de apariencia convencional y nueve con un patrón histopatológico señalado por los autores como reticulosis polimórfica. En estas lesiones, describieron un infiltrado ubicado sobre células reticulares y linfocitos maduros, con figuras mitóticas dispersas, núcleo prominente y pleomórfico. Los nueve pacientes fueron tratados con radioterapia y sobrevivieron más de cinco años. Los autores notaron similitud histopatológica en estos nueve casos con los granulomas de línea media previamente informados y postularon que puede existir una relación entre esos nueve casos con lesiones polimórficas y ciertos informes diagnosticados como granuloma letal de línea 
media. El mismo autor posteriormente agregando otro grupo de pacientes, separó los casos de GW, linfoma maligno y reticulosis polimórfica.

De los pacientes que permanecieron, varios resultaron con otras enfermedades: carcinoma, osteomielitis, enfermedades infecciosas específicas, sarcoidosis, etc. Ninguna entidad clínicopatológica de granulomatosis de línea media pudo ser documentada y recomendaron establecer la base diagnóstica en la clínica y en la patología. Kassel y col. (19), en 1969, habían señalado que después de haber sido excluidas infecciones y granulomas, el cuadro clínico de granuloma letal de la línea media puede ser producido por granulomatosis de Wegener, por reticulosis maligna de línea media o por linfoma maligno de uno de los tipos histopatológicos aceptados originando más confusión de la que ya existía.

Un estudio de McDonald y col. (20), en 1975, con 32 pacientes informó lo proteiforme de esta enfermedad y recalcó su similitud con la granulomatosis linfomatoidea descrita por Liebow (21); manifestó que la reticulosis polimórfica morfológicamente distinta de la granulomatosis de Wegener por la ausencia de granulomas epiteliodes, presencia de linfocitos atípicos, infiltrados angiocéntricos, ausencia de compromiso renal y cambios locales y difusos en el sistema respiratorio y que, además, puede evolucionar a una enfermedad linfoproliferativa (22) clásicamente ligada a linfoma y es más difícil de separar de esta enfermedad.

La reticulosis polimórfica responde a la radioterapia si las lesiones están bien localizadas, sus lesiones simulan las de la lepra (23) y, en ocasiones, responden a la ciclosfosfamida y a la prednisona. Se ha descrito como complicación por uso de inmunosupresores en el tratamiento de la fibrosis pulmonar (24) y asociada a linfoma de células T e infección por HIV, posiblemente por alteraciones clonales en su receptor. Los hallazgos radiológicos son inespecíficos (26). El TAC revela masa ósea y poca lisis y la resonancia (IMR) (27) es más útil porque diferencia la GW de una neoplasia o de un granuloma letal de línea media.
Desde nuestro punto de vista, pensamos que el término clínico de granuloma letal de línea media no es muy bien comprendido por el cuerpo médico, pues no hay claridad en la patogénesis de las lesiones de línea media; los aspectos histológicos deben ser correctamente interpretados por los clínicos y patólogos; la patogénesis de cada una de las entidades es diferente y no existe una base inmunogenética común. Actualmente podemos definir estas entidades clínicas de la línea media adecuadamente como los linfomas, la vasculitis granulomatosa de Wegener y las lesiones granulomatosas localizadas. Creemos que las lesiones granulomatosas localizadas tienen un mecanismo etiopatogénico caracterizado por una alteración en la presentación antigénica. Analizando esta observación, uno o varios agentes etiológicos pueden producir un defecto en la presentación antigénica, cuya respuesta inmunitaria tiene un substrato inmunogenético y la respuesta pueda ser adecuada o no, ocasionando la enfermedad. Esto lo podemos comprobar al presentar el primer y segundo pacientes de la serie; estos enfermos tenían como característica las lesiones localizadas en la línea media; nunca desarrollaron manifestaciones sistémicas como ocurre con los cuatro casos siguientes, no fue necesario un tratamiento con drogas inmunosupresoras (con excepción del primero por corto tiempo), evolucionaron favorablemente a tal punto que actualmente están asintomáticos (12 años y 23 meses) respectivamente. Es importante destacar en el caso número dos en los estudios de tinción con la técnica de peroxidasa inmunoperoxidasa, el infiltrado inflamatorio de la biopsia nasal es positivo para el marcador CD45RO ("memory cells").

Las células de memoria pueden congregarse en los infiltrados inflamatorios crónicos porque: 1) migran hacia los sitios de la inflamación; 2) se retienen debido a la interacción con otras células y la matriz proteica celular; y, 3) proliferan dentro de ellos.

La diferenciación de las células CD45RA+ o células primitivas a las células CD45RO + UCLH1+ o células de memoria se acompaña de un incremento en la expresión de unos marcadores de adhesión celular como CD2, LFA-3, LFA-1, ICAM- 
1 y VLA-4, y en la fosa nasal estas células se encuentran activadas parcialmente, así mismo ocurre con la expresión del receptor de IL2 y con las células de memoria que al separarse de la sangre periférica adquieren un volumen mayor y expresan mayor cantidad de LFA-1. El incremento en la expresión de receptores de adhesión sobre las células de memoria señalan una unión selectiva. Igualmente resaltamos la importancia de citocinas como interferon gamma y GM - CSF que pueden aumentar la función del fagocito in vivo (28). Danle y Doyle observaron que las células en reposo CD29+CD45RO o células T de memoria tieneh $2-3$ veces más capacidad para adherirse a las células endoteliales, que las células CD29-CD45R4; además, las citocinas incrementan la expresión de ELAM-1 y VCAM-1 de las células endoteliales y éstas se unen a las células de memoria $(29,30)$.

Los C-ANCA están dirigidos contra la proteinasa 3 , la mieloperoxidasa (MPO) y la elastasa, enzimas presentes en los gránulos primarios o azuróficos de los neutrófilos. La mayoría de ellos son anticuerpos de la clase IgG, aun cuando se han descrito ANCA de la clase $\lg M$ e $\lg A(31-34)$, se ha demostrado que tienen alta especificidad al asociarse con la granulomatosis de Wegener, al encontrarlos positivos se descartan entidades como sarcoidosis necrotizante y granulomatosis linfomatoide. La biopsia pulmonar abierta corrobora el diagnóstico (35). Sin embargo, en aquellos pacientes que tienen C-ANCA positivo, pero no hay un compromiso sistémico sino únicamente una lesión granulomatosa localizada, se debe tener cuidado en utilizarlo como marcador serólogico para plantear un diagnóstico de GW, ya que sabemos que en la forma localizada sólo el 30\% tienen C-ANCA positivos (36).

A través de la revisión hemos insistido que las granulomatosis centrofaciales tienen un comportamiento etiopatogénico clínico y de evolución muy particular, reconociendo que las formas limitadas son usualmente de mejor pronóstico, que responden más facilmente a la terapia (37), obligando a considerar estas presentaciones atípicas y recordando la utilidad y las limitaciones de los C-ANCA en estos casos (38). Es una entidad de pronóstico completa- mente diferente a lo que ocurre con la granulomatosis sistémica de Wegener por lo que debemos reconocer que no toda ganulomatosis nasal, senos paranasales, tráquea (43, 44) es una vasculitis granulomatosa de Wegener. En el enfoque de estos pacientes debe correlacionarse bien la clínica con la histopatología; investigar siempre si existe un compromiso sistémico que pueda orientar hacia una granulomatosis de Wegener.

La biopsia sola no es suficiente para el diagnóstico de GW; se ha demostrado que a nivel nasal tiene una sensibilidad del $52 \%(39,40)$ encontrándose con frecuencia los granulomas de origen infeccioso o por cuerpo extraño. La presencia de vasculitis es útil para el diagnóstico, pero su presencia no es obligada (14); en estos casos orienta encontrar granulomas en palisadas de tipo extracelular. No debe emplearse el término granulomatosis letal de línea media, sino que se debe estudiar cada paciente desde el punto de vista clínico y patológico y definir el diagnóstico de acuerdo con nuestra propuesta de clasificación.

Estas enfermedades confunden mucho al clínico, existen casos de obstrucción nasal conepistaxis y otitis media serosa que son comunes a entidades como cáncer nasofaríngeo (41); de ahí la importacia de la sospecha clínica precoz.

Eichel y col. (18) estudiaron 62 pacientes y 55 tenían otro diagnóstico; esto corrobora lo que hemos planteado acerca del conocimiento sobre estas enfermedades.

Considerar a la reticulosis polimórfica como precursora de una enfermedad linfoproliferativa y, en ocasiones, puede comprometer la piel y los pulmones confundiéndose con una GW (43).

Es importante analizar las piezas histológicas cuidadosamente y practicar estudios imnunohistoquímicos (44) que permitan identificar el origen de las células Ty la producción de interferón gamma (12), de otras citocinas y selectinas para poder explicar la inmunopatogénesis (45).

El tratamiento es diferente si es una reticulosis polimórfica; se trata con radioterapia (1), diferente al tratamiento de la GW o a la combinación de 
quimioterapia y radioterapia de la granulomatosis linfomatoidea (46).

Los casos de reticulosis polifórmica tienen mejor pronóstico que los linfomas típicos nasofaríngeos (47) y dicho término, para algunos, es sinónimo de granulomatosis linfomatoidea y hacen parte de las entidades que configuran el diagnóstico sindromático de granuloma letal de línea media (48).

\section{Referencias}

1. Wolf S M, Wilson, Braunwald, Issibacher, Peterdorf, et al. Midline granuloma. In: Harrison's Principles of internal medicine, 12 th Edition. New York: McGraw Hill Inc. 1991; 1471.

2. Friedmann I. Midline granuloma. Proc Roy Soc Med $1964 ; 57 ; 280$.

3. Pickens JP, Modica L. Currents concepts of the lethal midline granuloma syndrome. Otolaringol Head Neck Sur $1989 ; 6: 623$.

4. Case record of the Massachusetts General Hospital. N Engl J Med 1990; 332:116.

5. Bleil L, Manger B, Winler T. The role of antineutrophil cytoplasm antibodies, anticardiolipin antibodies, von Willebrand factor antigen, and fibronectin for the diagnosis of systemic vasculitis. Rheumatol 1990; 18:1199.

6. Fechner RE, Lamppin DW. Midline reticulosis. Arch Otolaryngol 1972; 95:467.

7. Cohen Tevaert JW, Van DerWonde FJ, Franci AS, et al. Assotiation between active Wegener's granulomatosis and anticytoplasm antibodies. Arch Inter Med 1989; 149: 2461.

8. McBride P. Photograhs of case of rapid destruction of the nose and face. Laryng 1987; 12:64.

9. Godman G, ChurJ.Wegener's granulomatosis, pahology review of the literature. Arch Pathol 1954; 58: 533.

10. Blatt IM, Holbrooke SD, Rubin P, et al. Fatal granulomatosis of the respiratory tract (lethal midline granuloma Wegener granulomatosis). Arch Otolaring 1959; 55:707.

11. Friedman J. The pathology of malignant granuloma of the nose. J Laring 1959; 73:242.

12. Walton E.W. Non-healing granuloma of the nose. J Laring 1959; 73:242.

13. Case record of the Masachussetts General Hospital. N Engl J Med 1992; 326:184.

14 Conn DL, Hunder GG. Vasculitis and related disorders. In: Kelley WN, Harris ED, Ruddy S, Sledge CB, Eds. Textbooks of Rheumatology. Philadelphia:WBSaunders, $1989 ; 1167$.

15. Iglesias A, Deulofeut H, Dubey D, et al. Functional deficiency of antigen presenting cells in the sinovial fluid of rheumatoid arthritis. Human Immunol 1992; 35:109.
16. Burtson $\mathrm{HH}$. Lethal midline granuloma, is it a pathology entity. Laringoscope 1959; 69:1.

17. Dagget RH, Hagheghi P, TerNeltaub RA. Nasal cocaine abuse causing an aggressive midline intranasal and pharingeal destructive process mimicking midline reticulosis and limited Wegener granulomatosis. J Rheumatol 1990; 17:838

18. Eichel BS, Harison EG, Devine KD, et al. Primary lymphoma of the nose including relationship to lethal midline granuloma. Amer J Surg 1966; 112:597.

19. Nassel S, Echevarría RA, Gozzo FP. Midline malignant reticulosis. Cancer 1969; 4:920.

20. Meclonad th J. De Reeme RA, Harison EG, et al. The protean clinical features of polymorphic reticulosis. Laringoscope 1976; 86:9.

21. Liebow AA, Carrington CRB, Friediman PJ. Lymphomatoid broncolamitosis. Hum Pathol 1972; 3:457.

22. De Reeme RA, Waland LH, McDonald TJ. Poly-morphic reticulosis, lymphomatoid granulomatosis: two diseases or one? May Clin Proc 1978; 53:634.

23. Adad SJ, Flury RN, Muñez A. Lymphomatoid granulomatosis vs. leproy. Hansenol-Int 1989; 14:32.

24. Suttner HJ, Enzmann H. Lethal midline granuloma as a result of long immunosupressive therapy. A case report. Laringorhinologie 1990; 69:660.

25. Bold JE, Ghali U, Bold S, et al. Angiocentric immunoproliferative lesion $T$ cell lymphoma and the acquired immune deficiency syndrome: a case report and review the literature. Cancer 1990; 66:2407.

26. Teng MM, Chan CY, Guo Coy, et al. Evaluation of polymorphic recitulosis. Neuroradiology 1990; 31:498.

27. Drake-lee AB, Milford CA. A review of the role of radiology in nonhealing granulomas of the nose and nasal sinuses. Rhinology 1989; 27:231.

28. Shapiro BL, Newburger PE, Klempner MS, et al. Chrarie granulomatosis diseases presenting in a 69 year an old man. N Engl J Med 1991; 325:1786.

29. Springer TA. Adhesion receptors of the immune system. Nature 1990; 346:425.

30. Claiman HN, Giorno RC, Sibold JR. Endothelial and fibroblastic activation in scleroma. Arthritis Rheum 1991; 34:1945.

31. Gross WL, Luderman J, Csernold E. Anticytoplasmic antibodies ANCA/ACPA in vasculitis: history, nomenclature, target antigens, clinical impact, and pathogenesis. Clin Immunol N letter 1990; 10:159.

32. Faln RJ, Jennette JCH.The third international workshop on antineutrophil cytoplamic autoantibodies. Am J Kidney Dis $1991 ; 2: 145$.

33. Wieslander J. How are antineutrophil cytoplasmic antibodies detected. Am J Kidney Dis 1991; 2:154.

34. Cohenevaert JW, Limburg P, Elena JD, et al. Detection of antibodies against myeloid lysosomal enzymes: A useful adjunte to classification of patient with biopsy proves necrotizing arthritis. Am J Med 1991; 91:59. 
35. Sauage CD, Winerals CG, Jornes, et al. Prospective study of radioimmunoassay for antibodies against neutrophil cytoplasm in diagnosis of systemic vasculitis. Lancet 1987; 1:1389.

36. Molle B, Spells W, Luderman J, et al. Anticytoplasmic autoantibodies: their immunodiagnostic value in Wegener's granulomatosis. Ann Intern Med 1989; 111:28.

37. Case record of the Massachussetts General Hospital. N Eng J Med 1992; 327:1938.

38. Case record of the Massachussetts General Hospital. N Eng J Med 1990; 323:1474.

39. Del Blanco EA, Flint A. Diagnostic usefulness of nasal biosy in Wegener's granulomatosis. Hum Pathol 1991; 22:107.

40. Colby tH V, Talegnar H, Speclls U, et al. Hum pathol 1991; 22:101.

41. Vones EE, Weichselbaum RR, Lippemen SM, et al. Head and neck cancer. N Engl J Med 1993; 328:184.
42. Eichel BS, Mabery TE. The enigma of the lethal midline granuloma. Laryngoscope 1968; 21:1367.

43. Case record of the Massachussetts General Hospital. N Engl J Med 1990; 322:116.

44. Dubois A, Rossi JF, Double EM, et al. Stewart's malignant midline granuloma periperal $\mathrm{T}$ cell lymphoma. Rev Laryngol Otorhinol 1989; 110:151.

45. Liford EH, Jr. Angiocentric immunoproliferective lesions: a clinicopathologic spectrum of post-thymic T-cell proliferation. Blood 1988; 72:1674.

46. Andrassy K, Rasenussin N. Treatment of granulomatosis disorders of the nose and paranasal sinuses. Rhinology 1989; 27:221.

47. Eichel BS, Harrison EG, Devine KD, et al. Primary lymphoma of the nose including a relationship to lethal midline granulome. Am J Sur 1966; 112:597.

48. Seideman JD. Case 2-1990, N Engl J Med 1991; 324. 